\title{
O uso da ludicidade durante o tratamento hemodialítico: vivências de acadêmicas de enfermagem
}

\author{
The use of playfulness during hemodialysis treatment: experiences of nursing students \\ El uso de la alegría durante el tratamiento de hemodiálisis: experiencias de estudiantes de \\ enfermeira
}

Wendy Larissa Costa da Silva ${ }^{1 *}$, Andreia Carleane Monteiro Magalhães ${ }^{1}$, Maria do Perpétuo Socorro Dionízio Carvalho da Silva ${ }^{1}$, Regina Barbosa da Costa $^{1}$, Micheli Souza de Oliveira ${ }^{1}$, Octavio Augusto Barbosa Mendonça ${ }^{1}$, Ana Cléo Borges Maia ${ }^{1}$, Maíra Gonçalves de Melo ${ }^{1}$, Neuza Alves Cardoso ${ }^{1}$, Mariana do Rosário Rivera² ${ }^{2}$

\section{RESUMO}

Objetivo: Relatar a percepção de acadêmicas de enfermagem de um projeto de extensão a respeito do uso da ludicidade durante o tratamento de pacientes hemodialíticos. Relato de experiência: $O$ projeto de extensão Atletas da Alegria: atividades lúdicas para sorrir iniciou em 2015, com intuito de proporcionar momentos de alegria, descontração e lazer, regido por atividades lúdicas. Observou-se que durante as ações lúdicas realizadas pelo projeto, os pacientes tem a percepção de que o tempo da sessão de hemodiálise é reduzido, e que durante as apresentações lúdicas os pacientes se sentem alegres, entusiasmados e emocionados, estes sentimentos são demonstrados através do riso e da interação com os integrantes do projeto, e também percebeu-se que durante as apresentações do projeto os pacientes se sentem mais confiantes em socializar e expressar seus sentimentos e opiniões. Considerações finais: Foi possível perceber uma quantidade elevada de pacientes em tratamento hemodialítico, porém uma carência de atividades distrativas e/ou lazer durante o mesmo. Se as atividades lúdicas forem bem planejadas, certamente contribuirão na sensação de minimização de tempo da sessão de tratamento, mas, principalmente, promoverão o bem-estar emocional do paciente.

Palavras-chave: Ludicidade, Hemodiálise, Atividades lúdicas.

\begin{abstract}
Objective: To report the perception of nursing students of an extension project regarding the use of playfulness during the treatment of hemodialysis patients. Experience report: The Atletas da Alegria extension project: playful activities to smile started in 2015, with the aim of providing moments of joy, relaxation and leisure, governed by playful activities. It was observed that during the playful actions carried out by the project, the patients have the perception that the time of the hemodialysis session is reduced, and that during the playful presentations, the patients feel joyful, enthusiastic and emotional, these feelings are demonstrated through the laughter and interaction with project members, and it was also noticed that during project presentations patients feel more confident in socializing and expressing their feelings and opinions. Final considerations: It was possible to notice a high number of patients undergoing hemodialysis, but a lack of distracting activities and / or leisure during the same. If the playful activities are well planned, they will certainly contribute to the feeling of minimizing the time of the treatment session, but, mainly, they will promote the patient's emotional well-being.
\end{abstract}

Keywords: Playfulness, Hemodialysis, Playful activities.

${ }^{1}$ Escola Superior Madre Celeste (ESMAC), Ananindeua - PA. *E-mail: wendylarissas@gmail.com

2 Universidade da Amazônia (UNAMA), Ananindeua - PA. 


\section{RESUMEN}

Objetivo: Informar la percepción de los estudiantes de enfermería de un proyecto de extensión sobre el uso de la alegría durante el tratamiento de pacientes en hemodiálisis. Informe de experiencia: El proyecto de ampliación Atletas da Alegria: actividades lúdicas para sonreír comenzó en 2015, con el objetivo de brindar momentos de alegría, relajación y ocio, regidos por actividades lúdicas. Se observó que durante las acciones lúdicas que realiza el proyecto, los pacientes tienen la percepción de que el tiempo de la sesión de hemodiálisis se reduce, y que durante las presentaciones lúdicas, los pacientes se sienten alegres, entusiastas y emocionales, estos sentimientos se demuestran a través de la risa y la interacción con los miembros del proyecto, y también se notó que durante las presentaciones del proyecto los pacientes se sienten más seguros para socializar y expresar sus sentimientos y opiniones. Consideraciones finales: Se pudo notar un alto número de pacientes en hemodiálisis, pero falta de actividades distractoras y / o de ocio durante la misma. Si las actividades lúdicas están bien planificadas, ciertamente contribuirán a la sensación de minimizar el tiempo de la sesión de tratamiento, pero, principalmente, promoverán el bienestar emocional del paciente.

Palabras clave: Alegría, Hemodiálisis, Actividades lúdicas.

\section{INTRODUÇÃO}

A Doença Renal Crônica (DRC) tem se tornado uma das doenças que mais acometem o ser humano em todo o mundo, transformando-se em um problema de saúde pública. A DRC é uma síndrome metabólica que advém de uma redução progressiva da atividade excretória dos rins. Muitas das vezes o paciente renal crônico não apresenta sintomas da doença enquanto não ocorre a diminuição da metade de sua função renal. A Insuficiência Renal Crônica (IRC) que é o estágio mais avançado da DRC caracteriza-se pela perda gradativa e inconvertível da função renal, ocasionando modificações em alguns sistemas e colaborando para o rebaixamento da capacidade do corpo em manter o equilíbrio hidroeletrolítico e metabólico ((LAGES JS, 2015; SOUSA FBN, et al., 2018).

A incidência da insuficiência renal crônica (IRC) eleva-se no mundo, assim como os recursos alocados em seu tratamento. Ao final de 2004, aproximadamente, 1,8 milhão de pacientes estavam submetidos às terapias de substituição renal. Desses, $77 \%$ encontravam-se em alguma forma de diálise, e $23 \%$ eram transplantados renais. No estágio mais avançado é necessário realizar o tratamento da doença através da hemodiálise ou do transplante renal. A hemodiálise é uma modalidade terapêutica que consiste na filtração de líquidos e toxinas presentes no sangue através de um equipamento que substitui as funções dos rins (ALCALDE PR e KIRSZTAJN GM, 2018; MENDES ML, et al., 2017).

Segundo Barbieri AR, et al. (2015) no Brasil, desde 1988, o Estado assegura legalmente a responsabilidade de disponibilizar assistência à saúde a todos através do Sistema Único de Saúde (SUS). Um direito à saúde que visa a realização de princípios como a universalidade, integralidade e equidade. No entanto, o acesso justo aos serviços de saúde exige o desempenho conjunto dos setores políticos e administrativos, devido a extensão do país e ao grande número de cidades com menos de 20.000 habitantes (SILVA FH, et al., 2015).

Dessa forma, em 1990 foi necessário fortalecer a gestão dos sistemas locais dos municípios, tornando os cuidados regionalizados. Por meio de um Plano Diretor de Regionalização (PDR), os estados precisavam trabalhar juntamente com o município visando o delineamento de regiões administrativas e estabelecer ações que poderiam ser realizadas localmente. Esse plano possibilitou a organização de novos serviços de saúde nessas regiões e reduziu as desigualdades criadas pelas distâncias e má distribuição dos serviços de saúde (ALBUQUERQUE MV, et al., 2017; PREUSS LT, 2018).

Porém, mesmo com as melhorias no SUS, ainda havia muitas reclamações de seus usuários. Sendo assim, em 2003, o Ministério da Saúde, criou a Política Nacional de Humanização (PNH), onde foram elaboradas estratégias, que viessem atender as necessidades dos usuários, proporcionando um acesso mais especializado e humanizado a saúde (MOREIRA MADM, et al., 2015). 
Dessa forma, para a estruturação de uma política adequada e de qualidade, destaca-se que a humanização deve ser compreendida como uma medida fundamental e não só mais um programa a ser executado de forma mecanizada, mas como uma política que abrange de forma integral o Sistema Único de Saúde. Ocorrendo assim uma aproximação dos profissionais e usuários, propiciando um serviço compartilhado, não somente entre as pessoas que necessitam e recebem os cuidados, mas envolvendo os profissionais e a gestão (VASCONCELOS MFF, et al., 2016; SILVA FH, et al., 2015).).

Implementando, assim, um meio de gerar saúde qualificada, com objetivo de incluir a maioria dos componentes deste contexto. A humanização deve ser compreendida de um modo mais abrangente em relação as condutas profissionais, no serviço hospitalar e na estruturação da unidade, visando um cuidado justo, altruísta e agradável, trazendo melhora para o processo de cura do paciente (MOREIRA MADM, et al., 2015.

A humanização como método proporciona a valorização do usuário, assegura a integralidade a população, a agilidade de acesso a todos, e dá ênfase aos determinantes valorosos da vida, realizando assim um trabalho dinâmico e satisfatório. Tal estratégia, têm refletido de forma positiva na prestação de cuidado aos grupos vulneráveis, dentre os quais estão os pacientes hemodialíticos que necessitam de uma atenção e cuidado redobrado durante o tratamento no âmbito hospitalar (RAMALHO CLS, 2017; FERREIRA LR e ARTMANN E, 2018).

Já que esses podem ter a sua qualidade de vida afetada na fase do tratamento, como: a perda de autonomia devido à dificuldade em se deslocar diariamente ou semanalmente para hospitais, a limitação para a realização das atividades da vida diária e muitas vezes não possui ajuda de familiares e amigos levando a dificuldade em lidar com uma doença irreversível e incurável, prejudicando tanto a saúde física quanto a psíquica do paciente (CRUZ MRF, et al., 2016).

As modificações na vida diária dos pacientes dialíticos são desgastantes, pois são submetidos a mudanças na rotina diária advindas do tratamento, como: o uso de medicamentos continuamente, redução hídrica e restrição de alguns alimentos. Neste cenário, a ludicidade surge como instrumento de humanização no tratamento hemodialítico, pois agrega valores significantes para o ser humano em todas as suas fases de vida, além disso, promove o equilíbrio emocional, torna mais leve as dificuldades diárias, ampliam as possibilidades do desenvolvimento social e, por fim, favorecem um sentimento de integralidade e unificação do paciente (FERREIRA RA, 2015; ASSIS BM, et al., 2016).

Este artigo tem por objetivo relatar a percepção de acadêmicas de enfermagem de um projeto de extensão a respeito do uso da ludicidade durante o tratamento de pacientes hemodialíticos, descrevendo os impactos das atividades lúdicas para o paciente em relação ao tempo da sessão do tratamento hemodialítico, os sentimentos gerados nos pacientes através da ludicidade e a contribuição da ludicidade na promoção da saúde mental/cognitiva do paciente durante o tratamento hemodialítico.

\section{RELATO DA EXPERIÊNCIA}

A proposta surgiu a partir do Projeto "Ler e Humanizar" criado em 2015, que levava leitura para pacientes hospitalizados adultos/crianças e acompanhantes de um hospital em Belém/PA, atividade que foi prevista para durar até final de 2015, mas foi interrompida em decorrência de um incêndio.

Com o reinício das atividades no hospital foi criado o projeto "Atletas da Alegria: atividades lúdicas para pacientes hospitalizados (dezembro/2015 a dezembro/2016), o intuito do projeto foi possibilitar novas alternativas de ação do projeto regidos pelo lúdico, como: apresentações teatrais, leituras, jograis e outros meios de entretenimento.

Em 2018, devido a expansão e reconhecimento do projeto através da imprensa local, as ações foram ampliadas, sendo realizadas em praças, escolas, casas de apoio, entre outros, desta forma não estavam mais restritas ao município de Belém. As ações do projeto que inicialmente eram mediadas por acadêmicos do curso de Educação Física em parceria com os dos cursos de Enfermagem e Letras de uma instituição privada de Ananindeua/PA, necessitou de novos integrantes para atender novas demandas. 
Sendo assim foi realizada uma seleção, dando oportunidade tanto para acadêmicos da instituição, quanto para discentes de outras instituições públicas e privadas que demonstraram interesse em participar de ações humanizadas. Dentre as novas demandas, no ano de 2017 , foi realizada a primeira ação no em um centro de hemodiálise em Ananindeua/PA no mês de maio em alusão ao dia das mães. Onde o projeto já contava com a participação de um número maior de integrantes, assim então podendo viabilizar ações em novos espaços.

Após a primeira apresentação na instituição, o projeto recebeu uma agenda pré-estabelecida, requisitando outras ações nas seguintes datas comemorativas: carnaval, dia das mães, festa junina e natal, sendo renovada anualmente. As ações no centro de hemodiálise contam com muitos momentos de descontração, através de músicas, danças e peças teatrais que são realizadas em todos os turnos de tratamento, logo todos os pacientes tem a oportunidade de presenciar as apresentações do projeto.

\section{DISCUSSÃO}

Observou-se que durante as ações lúdicas realizadas pelo projeto, os pacientes tem a percepção de que o tempo da sessão de hemodiálise é reduzido. Para que essa sensação de "tempo reduzido" ocorra é necessário utilizar diversos métodos para atrair a atenção dos pacientes, principalmente músicas alegres e dançantes, e os fazendo interagir através de palmas, cantorias e etc. Percebe-se que o lúdico tem a facilidade de dar a impressão de minimização do tempo da sessão do tratamento hemodialítico, com isto os pacientes relatam que nem vê o tempo passar.

Os pacientes frequentam os centros de hemodiálise, geralmente 3 vezes na semana e durante 0 procedimento necessitam ficar de 03 a 04 horas interligados a máquina, devido a essa sobrecarga do tratamento o mesmo torna-se exaustivo e entediante. Na proposta lúdica o paciente pode distanciar-se da realidade que está vivendo e desfrutar de momentos de alegria, distração e entretenimento. Sendo assim, formas de distração, que possam dar a percepção de redução do tempo de hemodiálise são benéficas para se desaperceber da passagem das horas e/ou minutos (AQUINO LQA, et al., 2016; CYRINO RS, et al., 2016; FERREIRA LR e ARTMANN E, 2018).

Percebeu-se que a realização de atividades lúdicas no centro de hemodiálise é considerada uma novidade, pois gerou mudanças na rotina do paciente tornando-a menos monótona e mais distrativa. Utilizava-se apresentações teatrais humorísticas e dançantes com o objetivo de entreter os pacientes, proporcionando um ambiente divertido e cheio de boas energias. Constatou-se que a atividade lúdica é o oposto de tempo ocioso e pode proporcionar momentos de distração, entretenimento, diversão e lazer.

A atividade lúdica modifica o estado de humor do paciente, promove distração e a oportunidade de participação em grupo, entretimento e lazer. No contexto hospitalar, o lúdico potencializa a vontade do ser humano de sentir ativo e propicia a absorção de experiências dolorosas e facilitam a convivência social. Durante a sessão de hemodiálise, os pacientes conversam com a equipe, dormem, lancham, assistem à televisão e leem, mesmo realizando essas atividades, o tempo demora a passar. Logo, o lúdico possibilita alternativas criativas para minimizar a monotonia, proporcionando ao paciente momentos de diversão e entretenimento (CRUZ DD, 2016; PAULA TB, et al., 2017; MENDES ML, et al., 2017).

Observou-se que durante as apresentações lúdicas os pacientes se sentem alegres, entusiasmados, emocionados e felizes, estes sentimentos são demonstrados através do riso e da interação com os integrantes do projeto. Com a utilização de músicas/danças antigas e regionais, os pacientes interagem com maior facilidade, assim se sentem à vontade para expressar seus sentimentos através de sorrisos e cantorias. Notou-se que as ações lúdicas em datas comemorativas instigam sentimentos diferentes nos pacientes, por exemplo: dia das mães e natal possuem uma característica mais familiar, emotiva e saudosa, logo os pacientes se sentem mais sensibilizados, chegando até mesmo a expressar o choro.

Já no caso das ações de carnaval e festa junina, os sentimentos demonstrados são os de alegria, entusiasmo, que são expressados através do riso, cantorias e interação com equipe lúdica. Percebe-se que o lúdico possui a potencialidade de gerar sentimentos de bem-estar, como: alegria, entusiasmo, emoção, 
felicidade, prazer, entre outros. Notou-se também que assim como o lúdico promove sentimentos positivos em alguns pacientes, em outros é percebida a desaprovação das atividades lúdicas realizadas devido questões particulares.

Lúdico é tudo que promove alegria, prazer e emoção. Jogos, dramatizações, festas, diversões e outras atividades de lazer que proporcionem momentos de mais leveza, descontração, ânimo, satisfação, criatividade, novos conhecimentos, inspirações e experiências são modos de conhecer o lúdico. O lúdico é tido como prazeroso, pois possui a capacidade de atrair o indivíduo de forma intensa e total, proporcionando um ambiente de entusiasmo, o que o torna uma atividade que tem a potencialidade de gerar uma sensação de euforia. A ludicidade tem a capacidade de provocar alegria e prazer, sentimentos que além de liberarem endorfinas, que são relaxantes musculares, ativa o sistema imunológico (RAMALHO CLS, 2017; FERREIRA RA, 2015; PAULA TB, et al., 2017).

Observou-se que as ações lúdicas geram nos pacientes sentimentos de afeição, amizade, carinho e gratidão, tanto com a equipe de enfermagem, quanto com os integrantes do projeto. Devido as atividades demandarem espontaneidade e comunicação de todos ao redor, a participação da equipe de enfermagem é essencial, assim sendo possível produzir vínculos maiores entre paciente e equipe e proporcionar um ambiente de tratamento mais prazeroso

A interação, amizade e carinho entre pacientes e integrantes do projeto foi fortalecida durante as repetidas ações em datas comemorativas, promovendo assim um ambiente mais acolhedor e menos hostil. Notou-se que a ludicidade tem a capacidade de promover sentimentos de afeição, carinho e gratidão entre pacientes e equipe de enfermagem; pacientes e integrantes do projeto.

A reciprocidade dos sentimentos estabelecidos pelas pessoas de forma sincera, concedem um significado único ao homem. As conexões fluem de forma positiva, transformando não só o sentimental,mas também o material, como a sala de diálise, assim mostrando outra perspectiva para este que é considerado um ambiente hostil. A enfermagem, no olhar teórico, é uma relação humana entre o paciente que precisa de cuidados e a equipe de enfermagem que deve identificar e responder a sua necessidade. Um vínculo sentimental entre paciente/enfermagem pode ajudar significativamente no aceitamento da doença, na adesão ao tratamento e, especialmente na melhora do âmbito de tratamento (SALIMENA AMO, et al., 2018; ALVES LO, et al., 2016).

Os profissionais de saúde que desejam prestar uma assistência holística devem levar em consideração que a ludicidade é um recurso terapêutico importante para a assistência. As atividades lúdicas proporcionam uma maior interação na relação entre profissional de saúde e paciente, assim promovendo uma assistência integral (PEREIRA CV e LEITE ICG, 2019).

Foi possível perceber uma quantidade elevada de pacientes em tratamento hemodialítico, porém uma carência de atividades distrativas e/ou lazer durante o mesmo. Se as atividades lúdicas forem bem planejadas, certamente contribuirão na sensação de minimização de tempo da sessão de tratamento, mas, principalmente, promoverão o bem-estar emocional do paciente.

A execução de ações lúdicas durante sessões de hemodiálise ou, principalmente, despertar a novidade, foi um desafio e um fato inusitado. Além de quebrar a rotina do centro, sensibilizou a equipe multiprofissional e minimizou a demora sentida nas sessões do tratamento. $O$ desenvolvimento de ações leva a crer que a proposição de inovações em relação ao cuidado de pessoas com doenças crônicas é possível. Porém, exige muito empenho e criatividade de parte dos profissionais, apoio da equipe e acolhimento por parte dos usuários.

\section{REFERÊNCIAS}

1. ALBUQUERQUE MV, et al. Desigualdades regionais na saúde: mudanças observadas no Brasil de 2000 a 2016. Ciência \& Saúde Coletiva, 2017; 22(4): 1055-1064.

2. ALCALDE PR, KIRSZTAJN GM. Gastos do Sistema Único de Saúde brasileiro com doença renal crônica. J. Bras. Nefrol., 2018; 40 (2): 122-129. 
3. AQUINO LQA, et al. Contribuições da Utilização de Atividades Lúdicas na Promoção da Resiliência em Pacientes Renais Crônicos em Tratamento Hemodialítico na Fundação Pró Rim - Unidade de Gurupi-TO. Amazônia Science \& Health, 2016; 4(3): 12-18.

4. ASSIS BM, et al. Mudanças na vida cotidiana de pacientes em terapia renal substitutiva. Revista Científica Faesa, 2016: 12 (1): 59-62.

5. ALVES LO, et al.Ações do enfermeiro ao paciente renal crônico: reflexão da assistência no foco da integralidade. J. res.: fundam. care. Online, 2016; 8(1): 3907-3921.

6. BARBIERI AR, et al. Hemodialysis services: are public policies turned to guaranteeing the access?. Cadernos de Saúde Pública, 2015; 31(7): 1505-1516.

7. CRUZ DD. A inserção do palhaço no ambiente hospitalar: experiências de um projeto de extensão. Em Extensão, 2016; 15(1): 133-140.

8. CRUZ MRF, et al. Descoberta da doença renal crônica e o cotidiano da hemodiálise. Ciência, Cuidado e Saúde, $2016 ; 15(1): 36$.

9. CYRINO RS, et al. Atividades lúdicas como estratégia de educação em saúde com idosos. Revista ciência em extensão, 2016; 12(03): 154-163.

10. FERREIRA LR, ARTMANN E. Elizabeth. Discursos sobre humanização: profissionais e usuários em uma instituição complexa de saúde. Rev. Ciênc. Saúde Coletiva, 2018; 23(5): 1437-1450.

11. FERREIRA RA. Atividades Lúdicas como estratégia durante as sessões de hemodiálise. Atualiza Cursos, 2015;1-11.

12. LAGES, JS. Controle e avaliação da DRC no SUS. Universidade Federal do Maranhão. UNA-SUS/UFMA. São Luís, 2015; 42p.

13. MENDES ML, et al. Diálise peritoneal como primeira opção de tratamento dialítico de início não planejado. J. Bras. Nefrol., 2017; 39(4): 441-446.

14. MOREIRA MADM, et al. Políticas públicas de humanização: revisão integrativa da literatura. Rev. Ciênc. Saúde Coletiva, 2015; 20(10): 3231-3242.

15. PAULA TB, et al. Potencialidade do Lúdico como Promoção de Bem-Estar Psicológicode Pacientes em Hemodiálise. Psicologia: Ciência e Profissão, 2017; 37(1): 146-158.

16. PEREIRA CV, LEITE ICG. Qualidade de vida especializada em saúde de pacientes em terapêutica hemodialítica. Acta paul. enferm., 2019; 32(3): 267-274.

17. PREUSS LT. A gestão do Sistema Único de Saúde no Brasil e as regiões de fronteira em pauta. Rev. Katálysis., 2018; 21(2): 324-335.

18. RAMALHO CLS. Ações de palhaçoterapia e efeitos de variação fisiológica em pacientes renais em hemodiálise. Dissertação (Mestrado) - Universidade Federal de Pernambuco, CCS. Programa de Pós-Graduação em Ciências da Saúde, Recife, 2017; 103 p.

19. SALIMENA AMO, et al. Sentimentos da pessoa em hemodiálise: percepção da equipe de enfermagem. Revista de Enfermagem do Centro-Oeste Mineiro, 2018; 8 (e2578): 1-5.

20. SILVA FH, et al. Experimentações e reflexões sobre o apoio institucional em saúde: trabalho a partir do HumanizaSUS. Interface (Botucatu), 2015; 19(55): 1157-1168.

21. SOUSA FBN et al. Pacientes com insuficiência renal crônica em hemodiálise: tratamento e diagnóstico. Rev. Investig, Bioméd., 2018; 10(2): 203-213.

22. VASCONCELOS MFF, et al. Entre políticas (EPS - Educação Permanente em Saúde e PNH - Política Nacional deHumanização): por um modo de formar no/para o Sistema Único de Saúde (SUS). Interface - Comunicação, Saúde,Educação., 2016; 20(59): 981-999. 